took her again, and were now told to go and get "irons." Irons were accordingly obtained and the patient wore them for some months. In the meantime the deformity continued to increase and the apparatus became so painful that it had to be discarded. It was at this stage that I was called in.

Physical examination showed that there was some measure of justification for the bone-setter's diagnosis. The patient walked with a peculiar waddling gait, which closely simulated that of double congenital dislocation, and there was slight lordosis present. Nevertheless, a careful examination of the joints, combined with the history of the case, convinced me that there was not, and never had been, any dislocation. The legs were markedly bowed, the thighs curving out from the pelvis to such an extent that when the child stood with heels together and toes at an angle of $45^{\circ}$ there was a gap of six inches between the knees. The right tibia bulged outwards suddenly as it neared the ankle-joint; the left was fairly straight. The pelvis appeared normal. There was slight left dorsal scoliosis, compensated by right lumbar divergence, and the girl was round-shouldered. The parents declared that her back, like her legs, had for 13 years been perfectly straight. For the rest, the patient seemed to be in fair health and spirits, possessed of a good appetite, and free from digestive disturbances. The leg and thigh muscles were well developed and powerful. There was no tenderness in the pelvis, lower limbs, or elsewhere. Menstruation seemed normal; the urine presented no peculiarities; pyrexia was absent. Examination of the thyroid region revealed nothing. Apart from the spinal curvature, which, as above mentioned, was stated to be recent, there was nothing to suggest that the child had ever suffered from infantile rickets - no beading of ribs, enlargement of radial epiphyses, or pigeon chest. Nor could I obtain a history of any of the symptoms of early rickets. Measles and chicken-pox formed the sum-total of her previous ailments.

Treatment. - As iron supports had been tried and found wanting, I ordered the patient to rest for six months. The mischief done by gravity might, I hoped, be overcome by a steady force in an opposite direction, and I therefore had a special apparatus constructed by an instrument maker. The patient lay on a hair mattress. Above the waist she was made as comfortable as possible with cushions, but from the buttocks downwards her body rested on a narrow platform of boards about 3 feet long by 18 inches wide. This was furnished with a perpendicular foot-piece to which the feet were strapped, heels together (with a pad between to prevent soreness), the toes spreading to an angle of about $45^{\circ}$. Around the waist was fitted a belt resembling a portion of a corset; from this a strip of canvas 2 inches wide was passed down on the outer side of each leg to be attached to the foot-piece below. Six bands, $2 \frac{1}{2}$ inches wide, consisting partly of canvas and partly of elastic webbing, and furnished with straps and buckles, were passed round both limbs at regular intervals from the thighs to the feet. They were held in position by passing through loops stitched to the side pieces, and it was possible by tightening the straps to exercise a graduated pressure in the direction of approximating the bowed members. In order to prevent the patient from easing the strain by raising her knees the legs were bound down to the wooden platform. The apparatus, as might have been expected, produced a certain amount of cramp, but she was able to bear it quite 16 hours out of the 24 .

Meanwhile the patient was given cod-liver oil, phosphorus, and virol; later she had the iodide of iron, and finally thyroid extract. Altogether, I treated her for nine months, two-thirds of which time she lay on her back. The results were disappointing. By the end of six months the legs had grown half an inch in length, and the knees came one and three-quarter inches nearer together; but it is questionable whether this slight improvement was due to anything other than the weight being taken off them. At any rate, an attempt to resume walking produced a rapid recurrence. All I could suggest now was a double osteotomy, followed by at least a year on a couch. Her people demurred to this, however, and I did not press them. Shortly afterwards they left the neighbourhood and I lost sight of the case.

To my mind the relationship between such cases as the above and infantile rickets appears more than doubtful. The rickets of early childhood is now generally admitted to be a disease of nutrition, and is readily amenable to suitable dietetic measures. That this girl, the daughter of well-to-do. country people, suffered from improper feeding is hardly probable. Mr. Clutton's patient was likewise of respectable parentage. I note, too, in his account the same absence of early rachitic history, the same resistance to treatment. Is it not better to admit frankly that we do not know the etiology of the affection? The most we can say is that the disease appears to be connected with the development of the sexual functions; and that, as in the case of those bony and arthritic lesions which occur during pregnancy and the menopause, it may be in some obscure way associated with changes in the internal secretions of the generative glands. Cockton Hill, Bishop Auckland.

\section{A CALCIFIED LEFT OVARIAN DERMOID, SEPARATED FROM ITS PEDICLE, TRANSPLANTED}

ON TO THE RIGHT BROAD LIGAMENT AND VESICAL PERI. TONEUM ; REMOVAL ON THE TENTH DAY OF THE PUERPERIUM FROM A 12 PARA.

BY FRANCES IVENS, M.B., M.S. LoND.,

HONORARY MEDICAL OFFICER FOR THE DISEASES OF WOMEN, LIVERPOOL STANLEY HOSPITAL.

INSTANCES of transplanted ovarian tumours were more often recorded by the early ovariotomists when operative measures were not readily undertaken and long-standing cases more frequently came under notice. Sir Spencer Wells ${ }^{1}$ refers to a case described by Dr. Atlee, who found a dermoid tumour post mortem in a woman aged 79 years. The presence of a tumour had been recognised 47 years before by Dr. Atlee's uncle. There was no pedicle, and the tumour was dependent upon adhesions for its vascular supply. Sir Spencer Wells himself operated upon a case where the tumour had been present 18 years. During that time the patient had married and had had three children, the tumour lessening with the progress of each pregnancy. There was no pedicle, the blood-supply having been kept up through the vessels of adhering omentum and mesentery. The patient was pregnant at the time and was delivered of a living child seven months after. Mr. Alban Doran ${ }^{2}$ described a case he witnessed which was operated upon by Mr. Knowsley Thornton in 1881. A woman, aged 34 years, had for seven years presented symptoms of an abdominal tumour, and in the intervil had given birth to four children. A spherical dermoid cyst of the size of a cricket-ball was removed. It was entirely detached from its pedicle and adherent to the omentum. The right ovary was cystic and was removed. The left Fallopian tube was obstructed and slightly dilated; close to it in the site of the ovarian ligament lay a short firm tag of fatty and partly calcareous tissue. In a paper on Twisted Pedicles Mr. Knowsley Thornton ${ }^{3}$ mentioned four instances of ovarian dermoids where the pedicle had completely separated.

Transplantation of ovarian tumours is probably usually preceded by torsion and gradual attenuation of the pedicle. As torsion occurs more frequently during pregnancy and the puerperium it is not remarkable that most of the recorded cases have occurred in multiparæ. The length of the pedicle and amount of play allowed are important factors, any drag after the twist has started being sufficient to cause the pedicle to give way. The tumour, usually an aseptic foreign body, transplants itself on to the nearest omentum or intestine. When sudden torsion takes place acute symptoms immediately arise resembling those of intestinal obstruction, and rupture of the tumour from hæmorrhage into its cavity or necrosis or suppuration may occur. If the twist is gradual there may be little to mark the event. Congestion of the tumour may be followed by atrophy. The nutrition is impaired, but adhesions may gradually form and augment the blood-supply. Fibrosis and calcification may follow. The atropied pedicle may rupture, and if the tumour is free it may find a new resting place in the abdominal cavity, plastic adhesions forming between it and the peritoneum, and providing a new blood-supply.

1 Spencer Wells: Ovarian and Uterine Tumours, p. 60, 1882 2 Doran : Tumours of the Ovary, London, 1884, p. 118 3 Knowsley Thornton : Rotation of Ovarian Tumours, International Journal, 1888, p. $\$ 57$. 
The following case is that of a woman, aged 40 years, and married 22 years, who was sent up to the Stanley Hospital by Dr. Gertrude M. Hutton as a case of pregnancy complicated by a tumour. The patient stated that she had married at 18 years and had had 11 children. Her first child was born without difficulty at seven months in 1887, her health during pregnancy having been good. She had a quick confinement and was attended by a medical man. In 1890, when four months pregnant, an attack of inflammation occurred, and the medical man who attended her thought she had a displacement. In 1891 a seven months' child was born after very bad health during pregnancy. With the fourth she was better, but severe "inflammation" occurred after the fifth, sixth, seventh, and eighth confinements, when she was attended by midwives. During the ninth pregnancy fainting attacks occurred, coming on generally when she was on her hands and knees scrubbing. With the tenth child she had the same poor health and trouble with micturition. In 1906, after the eleventh confinement, she recovered strength very slowly, and the periods were absent 14 months. On June 10th, 1908, amenorrhœe began and lasted until Sept. 4th, when hæmorrhage occurred, lasting until the end of the month. The patient then noticed that the pain, which hitherto had been on the left side, now occurred on the right side and in separate attacks. A short time later she became aware of the presence of a tumour on the right side. On this account she sought advice in November at the Dispensary for Women, and was sent on to the Stanley Hospital the same week. The patient was then about five months pregnant. A hard mass of the size of a fœtal head could be seen and felt in the right iliac fossa. Though not very moveable it could be pushed down partly into the pelvis and did not appear to be in close connexion with the enlarged uterus. Pressure caused severe pain. The diagnosis was uncertain, but the situation and consistency were rather in favour of a subperitoneal fibroid.

As the pain increased the patient was admitted on Jan. 3rd, when seven months pregnant. The temperature and the pulse were normal. The swelling was very obvious and gave the abdomen the appearance of a transverse presentation. After a few days' rest in bed the pain subsided and the patient was sent home with instructions to come up at the onset of labour. This she did on Feb. 1st. The house surgeon, Mr. M. Greer, reported that it was a posterior vertex presentation. Labour was unusually prolonged, although it was an eight months child, and the head showed onsiderable moulding. There was no excessive post-partum hæmorrhage. A hard mass could still be felt in the abdomen in front of, and quite distinct from, the uterus. The question of ovarian tumour was considered. The child showed little vitality and died in 24 hours. On the third day the patient's temperature ran up to $102^{\circ} \mathrm{F}$, bat quickly fell to normal. As the patient went on well and the uterus involuted I did not operate until Feb. 13th. The omentum was spread out over a tumour of the size of a fœtal head extending from the right iliac fossa towards the pelvis. On dividing the omentum deeper adhesions were apparent between the tumour, the vermiform appendix, and the right tube. The tumour was fixed by a broad base on to the anterior surface of the right broad ligament and peritoneal surface of the bladder. The adhesions were ligatured and divided. A large aperture in the right broad ligament was closed with a continuous catgut suture. A stump consisting of about three-quarters of an inch of the left tube remained attached to the uterus, the free end impervious. A scar indicated the former position of the left ovary, the infundibulo-pelvic ligament, and the ovarian ligament. The right tube and ovary were normal. The patient made a good recovery and left the hospital on the twelfth day after operation. She now looks well and is free from pain.

The tumour measures three and a half inches in diameter and is, roughly, circular in shape. Adhering to its surface can be seen the remains of omental and peritoneal adhesions. Microscopically, sections show the lining to be of squamous epithelium. The wall is densely fibrous, with areas of calcification. The contents resemble mortar, mixed with hair and oil.

In this case there is no history of acute symptoms to mark sudden axial rotation of the tumour. The pedicle may have begun to twist during the early months of the second pregnancy, for there is abundant evidence in the tumour that its blood-supply has been deficient for many years. Had it then become fixed in its final situation it could hardly have escaped the attention of medical men, midwives, or the patient herself for so many years. Complete separation probably took place in the third month of the last pregnancy, when, after hæmorrhage for some weeks, the pain changed its locality and the tumour was first noticed. It was now in a situation to cause a certain amount of obstruction and it is interesting that this was the only lingering confinement.

Abortion is believed to be common in cases of pregnancy associated with ovarian tumours, and this patient had several premature births. It is somewhat remarkable that in spite of the alleged mortality of 25 per cent. ${ }^{4}$ of untreated cases of ovarian tumour complicating pregnancy this patient escaped with her life through 12 confinements in 20 years. The expectant treatment of this case was based on a diagnosis of subperitoneal fibroid, and the patient was admitted to hospital with a view to operative treatment should serious obstruction to delivery occur. Had a diagnosis of ovarian tumour been made its removal during pregnancy would have been a matter of great difficulty on account of the very extensive adhesions.

Liverpool.

\section{A CASE OF OBLITERATIVE ARTERITIS.}

By R. ALLAN BENNETT, M.B. LoND.,

HONORARY MEDICAL OFFICER IN CHARGE OF ELECTRICAL DEPARTMENT TORBAY HOSPITAL, TORQUAY.

THE patient in this case is a woman, aged 52 years, who until 11 years ago had enjoyed fair general health. In October, 1898, she was seized, while resting quietly, by a sudden attack of pain over the heart, which lasted for some hours and departed as quickly as it came, leaving a sense of illness which has continued more or less ever since. The note of her previous history reads as follows: "Measles at 10 zears. Nervous breakdown at 20. Was refused for insurance at 23. Miscarriage 7 years after marriage, and again 13 years later slow recovery on both occasions." The family history was unimportant. As the patient describes it, she became conscious that she possessed a heart and blood-vessels, and only at rare intervals has she been free from the sensation. The feeling was most marked at night when she was quiet in bed, and she would lie, at one time listening to the heart beating loud and rapidly and to the blood coursing with a sense of power through her carotids, and at another, hearing it as though it were an exhausted clock, watching for every lingering pulsation, and wondering how many more there would be for her to count. Apart from the listlessness which accompanied the sensation of bodily illness, there was almost constantly a certain amount of pain, or at least discomfort, in the right arm, which could always be increased by slight exertion, and amounted sometimes to a degree beyond which the patient felt she could not go. With this there was a feeling of lifelessness and cold in the limb, and the skin over the back of the hand was often discoloured in a patchy manner, more especially when the pain in the limb reached its height. During the 11 years the disease had lasted there have been on several occasions acute attacks of illness, when the somewhat indefinite symptoms described have all been accentuated, and when pain in the chest (localised over the sternum and not spreading over the arm) has been constant and severe. During these periods the patient rested-now entirely and now in part, and always with the greatest benefit to herself. The pain and weakness experienced in the right arm have been felt, though to a less degree, in the right leg; the foot on this side is generally cold, and there is often a sense of insecurity when walking or even when standing quiet.

When first seen the patient looked ill and said that she was incapable of any exertion at all. The least movement brought on pain over the front of the chest and shortness of breath, and the right arm and hand became cold and livid, patches of bluish discolouration extending from the back of the hand up the arw. I'here was strong visible pulsation in the carotids, more marked on the right side, where the finger could feel a rough systolic purring thrill, which was absent on the left. On the left side, from a point below the

4 McKerron : Pregnancy, Labour, and Childbed with Ovarian Tumour. 1903. London. 